\title{
Bipartição escrotal associada à má formação prepucial em ovino Morada Nova: relato de caso
}

\author{
[Scrotal bipartition associated with preputial malformation in sheep \\ Morada Nova: case report] \\ T.M.V. Melo, J.A.C. Lima Filho, J.G. Silva, C.R.A. Amaral, F.R. Correia, M.O. Sampaio, \\ N.C.T. Vasconcelos, W.M.A. Souza, M.C.O.C. Coelho
}

Universidade Federal Rural de Pernambuco - Recife, PE

\begin{abstract}
RESUMO
As alterações anatômicas do aparelho reprodutor masculino de ovinos são pouco relatadas, especialmente a condição de bipartição escrotal. Devido à importância do esclarecimento sobre esta alteração anatômica, objetivou-se relatar o caso de um ovino da raça Morada Nova que apresentava bipartição escrotal associada à má formação prepucial. Observou-se que essa alteração pode ocorrer como condição de adaptabilidade a climas tropicais.
\end{abstract}

Palavras-chave: adaptação, bioclimatologia, bipartido, carneiro, testículo

\begin{abstract}
The anatomical changes in the male reproductive system of sheep are rarely described, especially the scrotal bipartition condition. Due to the importance of clarification of this anatomical change, we aimed to describe a case of a Morada Nova sheep that had scrotal bipartition associated with preputial malformation. It was observed that this change may occur as a adaptability condition to tropical climates.
\end{abstract}

Keywords: adaptation, bioclimatology, bipartite, ram, testicle

\section{INTRODUÇÃO}

$\mathrm{Na}$ caprino-ovinocultura, como em diversas outras criações, a escolha adequada tanto de matrizes quanto do reprodutor é fator primordial para incremento da produtividade $\mathrm{e}$ da rentabilidade. Os reprodutores devem ser selecionados com base na sua sanidade e eficiência reprodutiva, além de características genéticas desejáveis que possam ser transmitidas às suas crias, considerando que os machos contribuem com 60 a $80 \%$ das características genéticas do rebanho (Viu et al., 2006).

Dessa maneira, alguns pontos deverão ser observados na escolha e seleção dos animais, como, por exemplo, sua adaptabilidade às condições climáticas da região, a aptidão pretendida, a caracterização racial padrão, a capacidade reprodutiva e a libido, além do fato de que esses animais devem ser livres de defeitos e doenças infectocontagiosas (Viu et al., 2006). Outro parâmetro a ser considerado quando se busca maior eficiência na exploração pecuária é a interação animal-ambiente, pois as diferentes respostas do animal às peculiaridades de cada região são determinantes no sucesso da atividade produtiva (Neiva et al., 2004).

Os animais bem adaptados a um determinado meio ambiente apresentam algumas características que os diferenciam dos animais menos adaptados: manutenção ou pequena perda de peso durante situações de estresse, principalmente calórico; elevada taxa reprodutiva; elevada resistência a doenças e parasitos; baixa taxa de mortalidade; e elevada longevidade (Medeiros e Vieira, 1997). 
A reprodução é o indício mais positivo de adaptação de todos os animais a um determinado ambiente, pois, para um funcionamento eficaz na produção de espermatozoides, os testículos dos mamíferos devem ser mantidos em temperatura inferior à corporal, termorregulação esta que só é obtida com um adequado equilíbrio entre temperatura corporal e ambiental (Medeiros e Vieira, 1997).

Desta forma, é importante a seleção de animais que tenham eficientes mecanismos de dissipação de calor, para o desenvolvimento de tipos mais adaptados aos trópicos, por conseguinte mais produtivos (Medeiros e Vieira, 1997).

A bipartição escrotal é comumente relatada em caprinos criados no nordeste brasileiro, podendo ser considerada uma adaptação ao clima, a fim de amenizar os prejuízos causados na produção espermática sob elevada temperatura ambiente. Essa característica amplia a superfície de cada testículo exposta ao meio ambiente, propiciando melhor dissipação de calor e possibilitando um aumento na qualidade do sêmen e na eficiência reprodutiva desses animais em relação àqueles que não a possuem (Almeida et al., 2008).

Segundo Nunes et al. (2005), os caprinos portadores dessa condição apresentam epiderme escrotal mais espessa e maior número de glândulas sudoríparas e, consequentemente, maior produção de suor com um sistema termorregulador escroto testicular mais eficiente, já que tais glândulas no escroto podem produzir cinco vezes mais suor do que as da pele de outras regiões, em resposta a uma elevação da temperatura ambiental.

Tendo em vista que alterações anatômicas do aparelho reprodutor masculino de ovinos são pouco relatadas, especialmente a condição de bipartição escrotal, e a importância do esclarecimento sobre essa alteração morfológica, objetivou-se relatar o caso de um ovino da raça Morada Nova que apresentava bipartição escrotal e má formação prepucial.

\section{CASUÍSTICA}

O município de Venturosa está localizado no estado de Pernambuco e pertence à mesorregião do Agreste Pernambucano e à microrregião do Vale do Ipanema. O clima predominante é o tropical semiárido chuvoso, com verão seco. Localiza-se a uma latitude $08^{\circ} 34^{\prime 2} 9^{\prime \prime}$ sul e a uma longitude $36^{\circ} 52^{\prime} 27^{\prime \prime}$ oeste, em uma altitude de 530 metros, onde a temperatura média da região é de $35^{\circ} \mathrm{C}$ durante o dia e $20^{\circ} \mathrm{C}$ à noite, no período seco; no período chuvoso, $25^{\circ} \mathrm{C}$ dia e $15^{\circ} \mathrm{C}$ durante a noite. Nessa localidade, a criação de ovinos e caprinos segue um regime de criação predominantemente semi-intensivo, com a exploração de animais de raça com aptidão leiteira, contando com rebanho de em média 6.000 ovinos e 2.800 caprinos (Brasil, 2007).

Em visita técnica realizada em um sítio desse município, cuja criação de ovinos se destinava à reprodução e recria, foi atendido um ovino macho da raça Morada Nova, com cinco meses de idade, criado em sistema semi-intensivo.

Segundo relato do criador, tal ovino era proveniente de uma propriedade na qual o acasalamento consanguíneo é uma prática comum. O manejo alimentar no sítio era realizado com volumoso do tipo feno, silagem, capim de pasto e concentrados à base de ração e sal mineral específico para ovinos e água $a d$ libitum. O manejo sanitário incluía vermifugação e vacinação preventiva, além de higienização e desinfecção das instalações.

Ao exame clínico, observou-se que o animal estava em estação, apresentava escore corporal bom, aprumos sem defeitos e parâmetros fisiológicos, como frequência cardíaca, respiratória, temperatura retal e movimentos ruminais, dentro dos padrões de normalidade.

Ao exame de prepúcio e pênis, notou-se que o prepúcio apresentava óstio anormal, com abertura ventral e em forma elíptica, terminando cranialmente em fundo cego. $\mathrm{Na}$ tentativa de exposição peniana e retração prepucial, houve dificuldade por presença de tecido conjuntivo subcutâneo cranial à abertura, no fundo cego (Fig. 1).

Ao exame escrotal, os testículos apresentavam-se simétricos, acima do nível dos jarretes e localizados em escrotos independentes, separados ao nível inguinal. Revelou-se bipartição escrotal completa. Na palpação, os testículos se apresentaram com consistência tensoelástica, sensibilidade e mobilidade normais com tração e retração, ausência de líquido 
escrotal ou degeneração e temperatura local inalterada. No pênis, após exposição e palpação, também não foram encontradas alterações, assim como durante a palpação do epidídimo, escroto e cordão espermático.

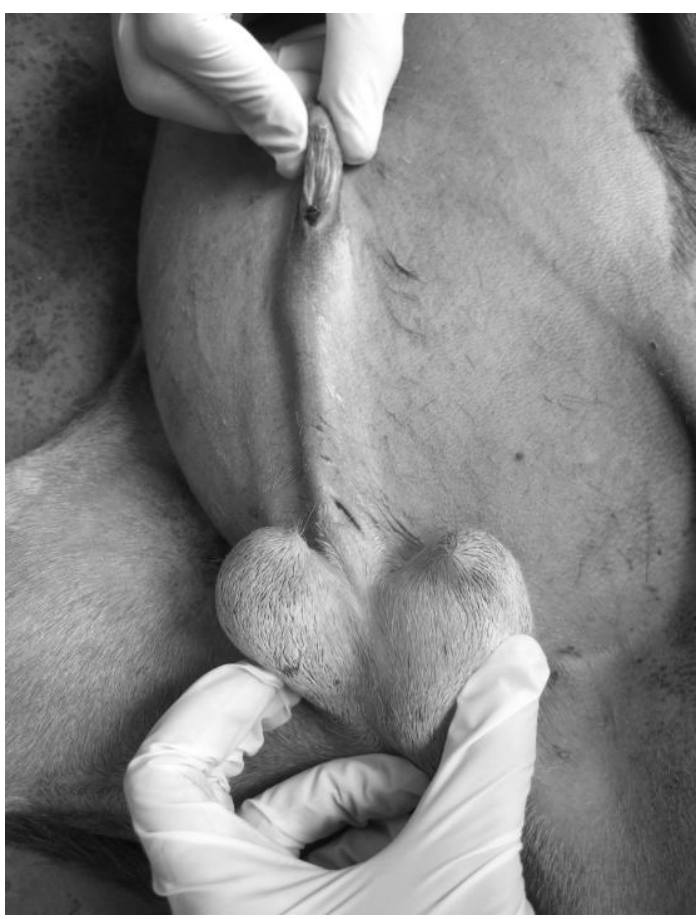

Figura 1. Bipartição escrotal e má formação prepucial em ovino.

\section{DISCUSSÃO}

$\mathrm{Na}$ literatura, pode-se encontrar relato de ocorrência de defeitos congênitos em variadas espécies de animais domésticos, porém há escassez de informações que esclareçam a etiologia dessas ocorrências (Dantas et al., 2010). Segundo Schild (2007), a frequência estimada de malformações anatômicas congênitas em ovinos é de 2,0\% $\mathrm{Na}$ propriedade estudada, ainda não havia sido constatado nenhum caso com tal alteração.

$\mathrm{O}$ fato de o criador relatar ter adquirido o animal de uma propriedade onde o cruzamento consanguíneo é comum leva a crer que essa alteração é originária de um defeito congênito, como cita Horovitz et al. (2005), quando afirma que tais malformações podem ter causa genética, ambiental ou desconhecida, mas que se supõe

Arq. Bras. Med. Vet. Zootec., v.65, n.4, p.1103-1106, 2013 serem ocasionadas por distúrbios funcionais ou estruturais no desenvolvimento fetal.

Quando comparada com outras patologias de origem genética do prepúcio, como fimose, parafimose e divertículo prepucial e do pênis, a exemplo de hipospadia e epispadia, percebeu-se que a alteração aqui relatada não apresentava semelhança com a descrição existente dessas outras, o que dificultou o diagnóstico preciso e possíveis medidas de prevenção. Tal resultado reforça a necessidade de mais estudos sobre essa alteração (Nascimento e Santos, 2003).

Com relação à condição de bipartição escrotal, as características climáticas podem ser apontadas como possíveis causas do aparecimento dessa alteração como um mecanismo de adaptabilidade ao clima do município de Venturosa - PE, juntamente com o fato de que, dos animais domésticos, os ovinos são um dos que apresentam mecanismos anatomofisiológicos mais propícios à sobrevivência em regiões de altas temperaturas (Bezerra, 2008)

Devido à escassez de literatura que descreva casos de bipartição escrotal na espécie ovina, o referencial utilizado para a discussão a seguir será o de caprino por ser a espécie mais semelhante com a relatada.

Segundo o criador, o animal apresentava uma boa libido, apesar das condições de alta temperatura da região (média de $35^{\circ} \mathrm{C}$ durante o dia, no período seco), corroborando os estudos de Machado Júnior (2006) no estado do Piauí, que demonstram que caprinos com o escroto bipartido acima de $50 \%$ do comprimento testicular tiveram um bom desempenho reprodutivo, sendo classificados, no período seco, como animais de boa libido e, no período chuvoso, como de excelente libido.

Levando em consideração o clima e a temperatura local, Vieira et al. (2008) sugerem que, nesses casos, o animal seja priorizado para reprodução, tendo em vista seus estudos em caprinos com bipartição, em que estes apresentavam sêmen de melhor qualidade. No entanto, apesar dos indicadores positivos para permanência do animal na reprodução, o proprietário optou pelo rufião, por não considerar essa característica desejável para seu plantel. 
A escolha de descarte do ovino, após seis meses do procedimento, deu-se provavelmente em razão de paradigmas culturais previamente impostos, em que a bipartição escrotal era considerada uma característica negativa, pois o animal com tal característica diferia dos demais e tinha sua fertilidade diminuída. Aliado a isso, existe a condição de que, em diversos padrões raciais, a bipartição acima de $1,5 \mathrm{~cm}$ é considerada um defeito eliminatório (Arco, 2012).

Diante desses fatos, Bezerra (2008) destaca a necessidade do conhecimento da tolerância e da capacidade de adaptação das diversas raças como forma de embasamento técnico à exploração ovina, bem como das propostas de introdução de raças em uma nova região ou mesmo o norteamento de programa de cruzamento, visando à obtenção de tipos ou raças mais adequadas a uma condição específica de ambiente.

\section{CONCLUSÃO}

A importância deste relato se deve à raridade de casos de bipartição escrotal em ovinos e sugere que essa alteração pode ocorrer como condição de adaptabilidade desses animais a climas tropicais.

\section{REFERÊNCIAS}

ALMEIDA, M.M.; CARVALHO, M.A.M.; MACHADO JÚNIOR, A.A.N. et al. Efeito do grau de bipartição escrotal sobre a vascularização arterial do escroto de caprinos nativos do Estado do Piauí. Braz. J. Vet. Res. Anim. Sci., v.45, p.167-173, 2008.

ARCO - ASSOCIAÇÃO BRASILEIRA DE CRIADORES DE OVINOS. Padrões Raciais. Disponível Online em: <http://www.arcoovinos.com.br/ index.asp?pag=padroes.asp>. Acessado em: $10 \mathrm{abr}$. 2012.

BEZERRA, W.M.A.X. Comportamento fisiológico e características de carcaça de diferentes grupos genéticos de ovinos criados no semi-árido paraibano. 2008. 72f. Dissertação (Mestrado em Medicina Veterinária) - Centro de Saúde e Tecnologia Rural, Universidade Federal de Campina Grande, Paraíba.
BRASIL. INSTITUTO Brasileiro de Geografia e Estatística. Produção da Pecuária Municipal - 2007. Disponível Online em: <http://www.ibge.gov.br/home/ estatistica/economia/ppm/2007/default.shtm>. Acessado em: 10 abr. 2012.

DANTAS, A.F.M.; RIET-CORREA, F.; MEDEIROS, R.M.T. et al. Malformações congênitas em ruminantes no semiárido do Nordeste Brasileiro. Pesq. Vet. Bras., v.30, p.807-815, 2010.

HOROVITZ, D.D.G.; LLERENA Jr., J.C.; MATTOS, R.A. Atenção aos defeitos congênitos no Brasil: panorama atual. Caderno de Saúde Pública, Rio de Janeiro, v.4, p.1055-1064, 2005.

MACHADO JÚNIOR, A.A.N. Influência da morfologia escrotal sobre a termorregulação, a biometria escroto-testicular e o comportamento sexual de caprinos nos períodos seco e chuvoso do estado do Piauí. 2006. 84f. Dissertação (Mestrado em Ciência Animal) - Universidade Federal do Piauí, Teresina.

MEDEIROS, L.F.D.; VIEIRA, D.H. Bioclimatologia Animal. Rio de Janeiro, 1997. 126p.

NASCIMENTO, E.F.; SANTOS, R.L. Patologia da reprodução dos Animais domésticos. 2.ed., Rio de Janeiro: Guanabara, 2003. 137p.

NEIVA, J.N.M.; TEIXEIRA, M.; TURCO, S.H.N. et al. Efeito do estresse climático sobre os parâmetros produtivos e fisiológicos de ovinos Santa Inês mantidos em confinamento na região litorânea do Nordeste do Brasil. Rev. Bras. Zootec., v.33, p.668678,2004

NUNES A.S. Morfologia do funículo espermático e dos escrotos em caprinos nativos do Estado do Piauí, com diferentes configurações escrotais. 2005. 57p. Dissertação (Mestrado em Ciência Animal) - Centro de Ciências Agrárias, Universidade Federal do Piauí, Teresina.

SCHILD, A.L. 2007. Defeitos congênitos, In: RIETCORREA F., SCHILD A.L., LEMOS R.A.A., BORGES J.R.J. (Eds), Doenças de Ruminantes e Equídeos. v.1. 3.ed. Pallotti, Santa Maria, 2007. p.2555 .

VIEIRA, R.J.; AZEVEDO, L.M.; CUNHA, L.A.L.; SALVIANO, M.B. Influência da morfologia escrotal e da época do ano na qualidade do sêmen de caprinos criados no Estado do Piauí. Rev. Bras. Cienc. Agr., v.3, p.376-380, 2008

VIU, M.A.O.; OLIVEIRA FILHO, B.D.; LOPES, D.T. et al. Fisiologia e manejo reprodutivo de ovinos: revisão. Rev. Eletr. Fac. Montes Belos, v.1, p.79-98, 2006. 